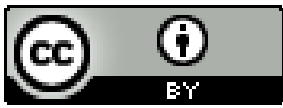

\title{
A GEOGRAFIA ESCOLAR E O ENSINO DAS RELAÇÕES ÉTNICO-RACIAIS: APONTAMENTOS A PARTIR DO CURRÍCULO REFERÊNCIA DO ESTADO DE GOIÁS
}

\author{
Lorena Francisco de Souzal \\ Camila da Conceição Reis Santos ${ }^{2}$
}

Resumo: Este artigo visa apresentar uma discussão sobre o ensino das relações étnicoraciais na geografia escolar a partir do Currículo Referência do Estado de Goiás. Passados 16 anos da implementação da lei 10639/03, que obriga o ensino da história da África e cultura afro-brasileira no ensino básico, ainda nos deparamos com o silenciamento das instituições escolares perante a uma agenda antirracista e a falta de capacitação pedagógica e conceitual de professores/as para tratarem sobre a questão. Nesse sentido, questionamos sobre como o ensino de geografia tem contribuído com o ensino das relações étnico-raciais e como os objetivos de aprendizagem estabelecidas no Currículo Referência do Estado de Goiás possibilitam esta abordagem. Para além das práticas docentes no âmbito escolar, problematizamos como se apresentam no Currículo Referência do Estado de Goiás as expectativas de aprendizagem no âmbito da Geografia para a formação cidadã e "inclusiva". O debate sobre a importância da ciência geográfica no respeito às diferenças e no tratamento das relações raciais é um caminho para a construção de um pensamento geográfico crítico e mobilizador de justiça social.

Palavras-Chave: Ensino de Geografia; Lei 10. 639/03; Cidadania; Currículo Referência do Estado de Goiás.

\section{SCHOOL GEOGRAPHY AND THE TEACHING OF ETHNIC-RACIAL RELATIONS: NOTES FROM THE REFERENCE CURRICULUM OF THE STATE OF GOIÁS}

Abstract: This article aims to present a discussion on the teaching of ethnic-racial relations in school geography from the Reference Curriculum of the State of Goiás. 16

\footnotetext{
${ }^{1}$ Professora do curso de licenciatura em Geografia da Universidade Estadual de Goiás - UnU Itapuranga, com doutorado em Geografia Humana pela Universidade de São Paulo. Tem experiência na área de Geografia Humana, com ênfase em ensino de Geografia e diversidade, relacionando gênero, relações étnico-raciais, formação de professores e ensino de Geografia. E-mail: loren.ueg@gmail.com

2 Licenciada em Geografia pela da Universidade Estadual de Goiás - UnU Itapuranga. E-mail: camilareis@hotmail.com
} 
years after the implementation of law 10639/03, which obliges the teaching of African history and Afro-Brazilian culture in basic education, we are still faced with the silencing of school institutions in the face of an anti-racist agenda and the lack of pedagogical and conceptual training of teachers to deal with the issue. In this sense, we question how the teaching of geography has contributed to the teaching of ethnic-racial relations and how the learning objectives established in the Reference Curriculum of the State of Goiás make this approach possible. In addition to teaching practices at school, we discuss as presented in the Reference Curriculum of the State of Goiás the expectations of learning in the context of Geography for citizen and "inclusive" training The debate on the importance of geographical science in respecting differences and in dealing with racial relations is a way to build critical geographical thinking and mobilizing social justice.

Key-words: Geography Teaching; Law 10.639/03; Citizenship; Reference Curriculum of the State of Goiás.

\section{LA GEOGRAFÍA ESCOLAR Y LA ENSEÑANZA DE LAS RELACIONES ÉTNICO-RACIALES: APUNTES DEL CURRICULO REFERENCIA DEL ESTADO DE GOIÁS}

Resumen: Este artículo pretende presentar una discusión sobre la enseñanza de las relaciones étnico-raciales en la geografía escolar a partir del Currículo de referencia del Estado de Goiás. Pasado 16 años de la implementación de la ley 10639/03, que obliga la enseñanza de la historia de África y la cultura afrobrasileña en la educación básica, aún nos deparamos con el silenciamiento de las instituciones escolares frente a una agenda antirracista y la falta de capacitación pedagógica y conceptual de profesores para trataren sobre la cuestión. En ese sentido, cuestionamos sobre como la enseñanza de geografía ha contribuido con la enseñanza de las relaciones étnico-raciales y como los objetivos de aprendizaje establecidos en el Currículo de Referencia del Estado de Goiás posibilitan este enfoque. Para además de las prácticas docentes en el contexto escolar, problematizamos como se presentan en el Currículo de Referencia del Estado de Goiás las expectativas de aprendizaje en el ámbito de la Geografía para la formación ciudadana e "inclusiva". El debate sobre la importancia de la ciencia geográfica en el respeto a las diferencias y en el tratamiento de las relaciones raciales es un camino para la construcción de un pensamiento geográfico crítico y movilizador de la justicia social.

Palabras-clave: Enseñanza de Geografía; Ley 10. 639/03; Ciudadanía; Currículo Referencia del Estado de Goiás.

\section{LA GÉOGRAPHIE SCOLAIRE ET L'ENSEIGNEMENT DES RELATIONS ETHNIQUES ET RACIALES: DES NOTES DU CURRICULO REFERÊNCIA DE L'ÉTAT DE GOIÁS}

Résumé: Cet article présente une discussion sur l'enseignement des relations ethnique et raciales dans la géographie scolaire à partir du Curriculo Referência de l'État de Goiás. Après 16 ans de la mise en œuvre de la loi 10.639/03 qui oblige l'enseignement de l'histoire de l'Afrique et la culture afro-brésilienne à l'école primaire, il y a encore le silence des institutions scolaires dans un agenda anti-raciste et la manque de capacité 
pédagogique et conceptuel des professeurs pour parler sur la question. En ce sens, nous remettons en question sur comme l'enseignement de Géographie a contribué avec l'enseignement des relations ethnique et raciales et comme les objectifs de l'apprentissage établie au Currículo Referencia de l'État de Goiás rends possible cette approche. Au-delà des pratiques des professeurs à l'école, nous problématisons l'usage du Currículo Referência de l'État de Goiás et les attentes de l'apprentissage dans la Géographie pour la formation citoyenne et " incluse ». Le débat sur l'importance de la science géographique au respect aux différences et au traitement des relations raciales est un chemin pour la construction d'une pensée géographique critique et mobilisateur de justice social.

Mots-clés: L'enseignement de Géographie; Loi 10.639/03; Citoyenneté; Curriculo Referência de l'État de Goiás.

\section{INTRODUÇÃO}

Atualmente temos percebido muitos avanços nas concepções e práticas da formação de professores que convergem para o entendimento de que ensinar geografia pode ser uma ação condizente com os princípios de uma sociedade democrática e consciente de sua posição no mundo. A formação de um/a professor/a de geografia coerente com esta concepção de democracia e, consequentemente, de cidadania, precisa estar atrelada a um entendimento de que os saberes docentes são formulados e construídos na prática em articulação com a teoria (CAVALCANTI, 2012), estendendo para a compreensão dos fundamentos da ciência geográfica, ensinar para uma intencionalidade social, ensinar conhecendo os/as alunos/as, suas histórias e identidades, ensinar refletindo sobre a sua posição no mundo e sua identidade profissional. Além desses elementos que constituem os saberes docentes, é de suma importância que os/as professores/as saibam por que é importante ensinar geografia e como ensiná-la para sujeitos e contextos específicos de cada realidade.

A prática docente em sala de aula ultrapassa o ensino da matéria em si e, portanto, mediar os processos de conhecimento é considerar os/as alunos/as como sujeitos ativos/as munidos de identidades, contextos sociais e culturais diversos com valores e expectativas distintas do que é estabelecido como norma social. As escolas são instituições sociais e apresentam em seu cerne realidades diversas que precisam ser consideradas mediante as definições curriculares e situações de aprendizagem. 
Mediante nossa concepção de prática docente e ensinar geografia calcada nos princípios apresentados, quando procuramos trazer o ensino das relações raciais na sociedade brasileira para a geografia escolar estamos nos referindo ao desafio desta disciplina em apresentar um elemento interseccional - no caso, a raça - como fator para o desmantelamento dos direitos sociais e políticos de uma parcela da população, para a segregação socioespacial, para a situação de refúgio e migração para o trabalho, para a violência doméstica e policial, em suma, para a desigualdade social em todos os aspectos. Nesse sentido, é compreender que as relações raciais estão presentes nos mais variados temas e conteúdos problematizados e pensados pela Geografia na escola.

De acordo com Santos (2013) é de suma importância a discussão sobre as relações raciais e a abordagem da lei 10.639/03 no ensino de geografia. Se pensarmos na função social desta disciplina como promotora de uma reflexão crítica sobre a realidade e a necessidade de uma formação cidadã, o ensino das relações étnico-raciais e, de maneira mais aprofundada, o conhecimento sobre o continente africano são pautas que não podem ser negligenciadas pela gestão e organização da escola, bem como para disciplinas que pretendem analisar e compreender a sociedade em sua dinâmica e complexidade.

Não é difícil presenciarmos na escola práticas pedagógicas negligentes com os conflitos raciais entre alunos, professores/as e comunidade escolar em geral, bem como a ausência de conteúdos que abordem a questão racial, seja na realidade brasileira, africana ou mundial. O silenciamento sobre as diferenças e as tensões raciais presentes no cotidiano de toda a comunidade escolar também é um elemento que camufla a inércia da escola em combater o racismo e as discriminações num sentido mais amplo.

Sabemos da importância da conduta docente enquanto elemento constitutivo da formação de sua identidade profissional no sentido de abordar a teoria e sua relação com a prática para então refletir sobre ela e buscar intervir na realidade, no entanto, ao tratarmos de temáticas presentes no cotidiano escolar, nota-se uma dificuldade em apresentar elementos no campo do currículo escolar e das disciplinas que problematizem a realidade social excludente, a desigualdade, a discriminação a grupos politicamente minoritários.

A geografia enquanto um campo disciplinar na escola deve se atentar para a leitura da realidade a partir da espacialidade e essa ação precisa estar equiparada ao entendimento sobre as diferenças, sobre as relações sociais imbuídas no espaço geográfico. Se isentar 
do entendimento sobre as relações de poder que permeiam as relações sociais nas intersecções de gênero, raça, etnia, geração e classe é não compreender a geografia enquanto uma ciência social preocupada com a formação cidadã e a justiça social. Segundo Tonini e Kaercher,

[...] a escola e a geografia podem contribuir para a ampliação da cidadania e da precária democracia brasileira; defendendo que tais temas, ainda que polêmicos e conflitivos, devam ser trabalhados de forma argumentada e reflexiva na escola, porque estão a todo momento na vida e nos meios de comunicação (TONINI e KAERCHER, 2015, p. 55).

Esta afirmação representa uma defesa a um ensino de geografia ancorado na compreensão de uma sociedade que é plural, é diversa e, como tal, apresenta percalços e desigualdades em virtude das heranças históricas e culturais. Como salienta Santos (1991), a educação acompanha as mudanças ocorridas na ciência e na sociedade. Os caminhos da educação parecem apontar no sentido de cultivar a heterogeneidade, a flexibilidade e a diferença, princípios estruturantes na sociedade atual, no entanto, as relações étnico-raciais são encaradas, muitas vezes, como tabus no espaço escolar, sobretudo devido à incipiente formação docente para o tratamento das diferenças, a falta de acesso a materiais didáticos e paradidáticos que abordam a questão e, no caso da geografia escolar, a dificuldade em relacionar a ciência geográfica em seu corpus teóricoconceitual, ao tratamento destas temáticas.

$\mathrm{O}$ ensino das relações étnico-raciais e o respeito às diferenças devem ser trabalhados em todas as áreas do conhecimento, o que significa que os cursos de formação de professores/as de Geografia também precisam referenciar em seu projeto político pedagógico a necessidade e importância do tratamento destas temáticas para práticas sociais cidadãs.

\section{A DISCUSSÃO RACIAL NAS ESCOLAS}

A escola é um espaço social constituído de diferenças, sejam elas sociais, raciais, de gênero e sexuais. Dessa forma, cabe ao professor a tarefa de mediar harmonicamente a construção de um espaço acolhedor que contemple dentro e fora do ambiente escolar as 
diferenças, sociais, culturais, étnico-raciais e de gênero, reafirmando a necessidade da escola estar cada vez mais aberta ao diálogo, como aponta Munanga

(...) em vez de opor igualdade e diferença, é preciso reconhecer a necessidade de combiná-las para poder construir a democracia. É nessa preocupação que se coloca a questão do multiculturalismo, definido como encontro de culturas, ou seja, a existência de conjuntos culturais fortemente constituídos, cuja identidade, especificidade e lógica interna devem ser reconhecidas, mas que não são inteiramente estranhas umas às outras, embora diferentes entre elas. (MUNANGA, 2008).

Sabemos que a escola tem um papel fundamental na construção do pensamento crítico, e transformador para o aluno. $\mathrm{O}$ professor deve estar atento às questões relacionadas ao racismo que em algumas situações passam despercebidas, seja pela dificuldade em confirmar a existência do racismo, seja por não o identificar em práticas cotidianas. Essa dificuldade se dá pela reprodução de uma história social marcada pelo mito da democracia racial e apagamento da exclusão social a partir deste recorte.

Apesar da ampla consideração de que existe tolerância e respeito às diferenças em nosso país, os aparelhos midiáticos reforçam uma representação social negativa sobre a corporeidade e o sujeito negro, enquanto perpetua um referencial positivo e convencional aos sujeitos brancos. A imagem do negro exposta de forma negativa em situação de inferiorização se contrapõe a do sujeito branco, muitas vezes representados como intelectual, belo e bem sucedido, indicando os padrões branco e eurocentrados como modelos adequados de sociedade.

Para que haja a transformação dos pensamentos e atitudes dos alunos é muito importante que ocorra o debate em sala de aula e discussão sobre a valorização de cada matriz racial, fazendo uso de material didático de qualidade, livros, projetos, filmes, teatro etc. Isso tudo precisa ser parte do planejamento docente desde o início das séries iniciais para que a criança cresça com uma concepção de que o pertencimento racial não determina desenvolvimento cognitivo, moral, emocional e ético nas pessoas. Para Cavalleiro (1998) as escolas, assim como outras instituições, estão repletas de práticas racistas e discriminatórias que prejudicam em demasia o aspecto emocional e cognitivo de crianças e adolescentes, sobretudo os negros. Mesmo com essa realidade, as escolas ainda tratam de maneira descompromissada e negligente o combate a tais práticas que, 
consequentemente, consolidam uma percepção negativa sobre a produção de pesquisadores/as e intelectuais negros/as que denunciam o racismo nas esferas sociais, bem como fortalece uma formação de indivíduos com ideias e comportamentos hierarquicamente racializados (BOTELHO, 2000).

Sabemos o quanto é importante a discussão a respeito da diversidade racial nas escolas, uma vez que elas têm o papel fundamental de informar, construir/produzir conhecimento e apresentar a diferença como um princípio humano, defender a justiça social e o respeito a todos/as.

Ser negro para muitos alunos é encarado como algo negativo, não há ainda muitos espaços sociais de aceitabilidade de uma identidade negra afirmada, o que reforça as consequências drásticas do racismo e da falta de referenciais positivos sobre a identidade negra. Mesmo que tenhamos hoje um aumento significativo de referenciais negros/as na televisão e redes sociais, no campo da micropolítica ainda é tímida a intervenção positiva sobre a identidade negra. Por isso, ao acreditarmos numa educação anti-racista e equânime, o/a professor/a de geografia deve inserir de forma positiva e responsável conteúdos concernentes à formação da população brasileira, territórios étnicos, desigualdade social, migrações, a geografia e a história do continente africano e sua importância no contexto social brasileiro. O racismo, enraizado no contexto social e cultural é um mecanismo de exclusão e desigualdade e o debate sobre os direitos sociais e políticos dos sujeitos é um importante caminho para uma educação geográfica atenta à formação cidadã.

\section{A LEI 10639/03 NO ENSINO BÁSICO: A VALORIZAÇÃO DA HISTÓRIA AFRICANA E CULTURA AFRO BRASILEIRA NOS CURRÍCULOS ESCOLARES}

A implementação da Lei 10.639/03 alterou a Lei de Diretrizes e Bases da Educação Nacional (LDB), tornando obrigatório o ensino da história da África e cultura afro brasileira nos currículos escolares. $\mathrm{O}$ advento dessa Lei é considerado um avanço em relação à valorização de parte da história do país e dos diferentes povos que o compõe, todavia, é relevante destacar que esse reconhecimento foi fruto das reivindicações dos movimentos sociais negros ocorridos a partir dos anos 1970 (PEREIRA; SILVA, 2012). 
Pereira e Silva (2012) destacam que nos anos 1980 vários pesquisadores observaram a alta evasão escolar de alunos/as negros/as, relacionada à vulnerabilidade social de parte dessa população, o racismo institucional, bem como a ausência de abordagens relevantes sobre o negro no Brasil. Na mesma época, vários movimentos de valorização negra ganharam intensidade, entre eles a Marcha Zumbi dos Palmares em Brasília, em 1995, no contexto das comemorações do tricentenário da morte de Zumbi dos Palmares, que foi um importante mecanismo de pressão ao governo de Fernando Henrique Cardoso pela implementação de políticas públicas de combate ao racismo e a inclusão de disciplinas de estudos africanos nas escolas públicas da Bahia.

Dias (2008) aponta, como decorrência da mobilização de intelectuais negros e não-negros comprometidos com uma educação anti-racista, a importância da publicação dos Parâmetros Curriculares Nacionais na década de 1990 que inclui em um de seus volumes o tema transversal "Pluralidade Cultural", no qual a questão racial aparece como tema a ser trabalho, partindo do princípio de que a diversidade racial do Brasil é positiva e constituinte da formação social brasileira. O então ministro da Educação Paulo Renato divulgou o fato de este volume ser incluído como uma das ações do Ministério da Justiça em prol das políticas de igualdade racial, bem como a inclusão de negros e negras na publicidade do Ministério a partir de 1995 constituir um importante passo na efetivação desta igualdade (DIAS, 2008).

Já no governo Lula, em 2003, a LDB sofre uma alteração para a inclusão da Lei 10.639 no ensino básico e a inclusão do dia 20 de novembro como data comemorativa ao Dia da Consciência Negra no calendário escolar. Em 2004, é lançado pelo Ministério da Educação e pela Secretaria Especial de Políticas de Promoção da Igualdade Racial, o Plano Nacional de Implementação das Diretrizes Curriculares Nacionais para a Educação das Relações Étnico-raciais e para o ensino de história e cultura afro-brasileira e africana.

As Diretrizes referendadas aqui corresponderam a um importante documento que buscou, teórica e pedagogicamente, superar o tema e a discussão sobre a pluralidade cultural apresentada pelos PCNs na medida em que propõe desenvolver políticas de reparação e de ação afirmativa aos/às negros/as. Esse documento trouxe, do ponto de vista legal, a discussão das relações raciais para a escola e o combate ao racismo, independente do currículo de cada disciplina. 
Também redigido por especialistas, no âmbito do campo especificamente pedagógico, o texto do parecer aprovado pelas "Diretrizes" possui um tom claramente mais político que o dos PCNs, já que diretamente relacionado à questão do combate ao racismo. De maneira inequívoca, educadores diretamente ligados aos movimentos negros respondem agora pela redação do documento. Nesse sentido, o parecer se propõe "oferecer uma resposta, entre outras, na área da educação, à demanda da população afro-descendente, no sentido de políticas de ações afirmativas, isto é, de políticas de reparações, e de reconhecimento e valorização de sua história, cultura, identidade" (ABREU e MATOS, 2008).

Por certo, as reivindicações dos movimentos sociais negros organizados foram importantes agentes na construção das diretrizes, aliados às pesquisas de professores/as e educadores/as sobre os impactos do racismo no ambiente escolar e no currículo.

Como salienta Gomes (2011), os movimentos negros foram instancias problematizadoras ao indagarem a exclusividade do enfoque sobre a classe social presente nas denúncias da luta dos movimentos sociais da época. Portanto, "as suas reivindicações assumem caráter muito mais profundo: indagam o Estado, a esquerda brasileira e os movimentos sociais sobre o seu posicionamento neutro e omisso diante da centralidade da raça na formação do país” (GOMES, 2011, p. 111). O Movimento Negro organizado buscou, nesse interim, compreender a questão racial como uma forma de opressão e exploração estruturante das relações sociais e econômicas brasileiras no sistema moderno produtor de mercadorias e apresentar essa demanda também aos movimentos sociais de esquerda, pressionando as políticas públicas no campo da educação. Desse modo,

As questões como a discriminação do negro nos livros didáticos, a necessidade de inserção da temática racial e da História da África nos currículos, o silêncio como ritual a favor da discriminação racial na escola, as lutas e a resistência negras, a escola como instituição reprodutora do racismo, as lutas do Movimento Negro em prol da educação começam, aos poucos, a ganhar espaço na pesquisa educacional do país, resultando em questionamentos à política educacional. Desencadeia-se um processo de pressão ao Ministério da Educação, aos gestores dos sistemas de ensino e às escolas públicas sobre o seu papel na superação do racismo na escola e na sociedade (GOMES, 2011, p.112 e 113).

A demanda política sobre as relações raciais na escola e nos conteúdos escolares torna-se, a partir daí, uma realidade permanente, no entanto, ainda em sua maioria protagonizada por professores/as e pesquisadores/as negros/as que têm, além 
disso, reivindicado o reconhecimento, a valorização e a afirmação da identidade e dos direitos dos/as negros/as brasileiros/as.

A inserção da temática racial nos conteúdos de História se apresenta de forma mais concreta nos materiais didáticos e paradidáticos, uma vez que o foco da lei é, de fato, aproximar o contexto histórico das espacialidades negras no território brasileiro e aproximá-la da história do continente africano. Para nós, professores/as pesquisadores/as do campo do ensino de geografia, o desafio apresentado para esta ciência enquanto disciplina escolar é a aproximação de conteúdos interdisciplinares, sejam da História, da Sociologia, da Antropologia, com conteúdos próprios da epistemologia da Geografia.

Em sala de aula, a Geografia tem um papel fundamental na transformação social pelo fato de abranger conteúdos e contextos sociais em sua espacialidade, além de possibilitar a construção de um pensamento sobre o espaço, ou seja, um pensamento geográfico. Conteúdos como o referente à formação da população brasileira são geradores de conhecimento e reconhecimento do Brasil como país heterogêneo e multirracial. Apesar disso, ainda vemos que esse conteúdo nos livros didáticos de geografia não aprofunda no trato sobre a diversidade étnico-racial da população, fatores urbanos que atingem negros/as e brancos/as de maneira desigual, territórios negros, recortes de raça e gênero para dados socioeconômicos e educacionais, dentre outros. É nesse sentido que Mota (2017) denuncia que todo conteúdo de uma disciplina escolar é "composto e organizado por narrativas cujo fim é contar o seu sentido e o seu significado social para alguém" (p.75). Se o ensino de geografia não lida com tais temáticas de maneira relevante ou que faça sentido no entendimento de uma espacialidade é reflexo da negação de narrativas que rompem com a perspectiva colonialista de mundo.

Nesse sentido, Santos (2011) chama a atenção sobre a importância de a implementação da lei problematizar o silenciamento e lugar social do negro na sociedade brasileira.

A lei reposiciona o negro e as relações raciais na educação - transformado em denúncia e problematização o que é silenciado (como, p. ex., o racismo no cotidiano escolar), chamando a atenção para como conhecimentos aparentemente "neutros" contribuem para a reprodução de estereótipos e estigmas raciais para o racismo". (SANTOS, 2011, p. 5). 
Há muitas barreiras que impedem o cumprimento da lei com eficácia, pois até mesmo os/as professores/as sentem dificuldades em trazer essa discussão para sala de aula, a falta de informação e conhecimento em suas formação inicial e continuada, falta de prioridade, o desinteresse a materiais didáticos voltados ao tema, uma visão de mundo reducionista e fechada ao tratamento da diferença interferem diretamente nas práticas pedagógicas em sala de aula e na escola.

\section{O ENSINO DE GEOGRAFIA NO CONTEXTO DA VALORIZAÇÃO DAS}

\section{DIFERENÇAS}

A temática racial é um importante elemento para a construção de uma formação cidadã a partir da educação geográfica. Discutir e fomentar a formação cidadã é um dos princípios do ensino de geografia. De acordo com Cavalcanti e Souza (2014), o ensino de Geografia precisa superar a assimilação passiva e reprodutiva de conteúdos geográficos, pois necessita promover o desenvolvimento amplo do aluno para atuar como cidadão.

Ao acreditar nos princípios básicos que regem o conceito de cidadania, que vai além da concepção política de direito ao voto, reconhecemos que o exercício da mesma está relacionado a uma conscientização sobre a participação na vida coletiva, no respeito à diversidade, emancipação social e empoderamento (BENEVIDES, 2004). A escola é um espaço social fundamental para a execução dos princípios da cidadania, pois de acordo com Pereira (2011),

vemos a escola como espaço que pode permitir o aprofundamento da vida democrática, na medida em que ela possa se tornar um espaço realmente público e que ensine e enseje a construção de outros espaços públicos, onde a diferença pode ser vivida e experienciada sem a marca do julgamento alheio (2011, p.21).

Essa reflexão nos ajuda a pensar que esta instituição social acolhe, a priori, a todos/as sem distinção. A escola para todos/as é um ganho social, político e histórico e o que compreendemos por educação inclusiva é um fato. Se ela está aberta a todas as diferenças possíveis em nossa sociedade, é nela que essas diferenças devem ser acolhidas e integradas a um "sistema que lhes permita marcar sua singularidade em meio à diversidade" (2011, p.22). 
Se a cidadania é conjunto de valores, ações e instituições comuns que integram os indivíduos para fazerem valer um recíproco reconhecimento enquanto membros de uma comunidade, ela apresenta um desafio mais amplo à intervenção política, social e pedagógica para transformar práticas discursivas tradicionais em questões de ética e cidadania (TONINI, 2011).

Sabemos dos avanços estabelecidos no campo das políticas educacionais no que se refere à valorização da identidade negra como aspecto da formação social brasileira, práticas pedagógicas voltadas para a valorização das diferenças e superação das desigualdades sociais, de gênero e raça na escola. Nesse sentido a geografia tem em seu papel enquanto ciência social atentar às realidades sociais e ao analisar esta realidade permitir o entendimento sobre justiça social que equivale, entre outros aspectos, a promoção de direitos sociais e políticos aos grupos sociais invisibilizados e inferiorizados.

As práticas docentes na escola observadas por nós têm mostrado que a restrição e consulta ao livro didático, muitas vezes, molda o ensino de geografia. De certa forma, os conteúdos são trabalhados a partir da sequência apresentada nos livros e completados pelas determinações das orientações curriculares. Estas, por sua vez, são denunciadas como responsáveis pelo engessamento do tratamento do conteúdo, devido à cobrança da gestão escolar para o cumprimento total do documento.

Embora tenha amplas condições de aprofundar certas discussões, observamos que a geografia trabalhada na escola ainda tende a apresentar com mais ênfase conteúdos relacionados a formação territorial e econômica, mas a formação política, o acesso a direitos à população, a análise crítica sobre as desigualdades sociais, raciais e de gênero não são enfatizadas como caminhos para uma formação cidadã.

A geografia possui um referencial que deve ser utilizado para construção de uma realidade discutindo situações em que insere o aluno no cerne da comunidade onde vive, levando a discussões e abordagens de soluções para os problemas detectados, o aluno precisa ser levado para o conteúdo geográfico para assim participar da construção de um pensamento geográfico que compreenda a justiça social como um mecanismo fundamental para uma sociedade democrática. Segundo o Ministério da Educação: 
O ensino de Geografia pode levar os alunos a compreender de forma mais ampla a realidade, possibilitando que nela interfiram de maneira mais consciente e propositiva. Para tanto, porém, é preciso que eles adquiram conhecimentos, dominem categorias, conceitos e procedimentos básicos com os quais este campo do conhecimento opera e constitui suas teorias e explicações, de modo que possam não apenas compreender as relações socioculturais e o funcionamento da natureza às quais historicamente pertence, mas também conhecer e saber utilizar uma forma singular de pensar sobre a realidade: o conhecimento geográfico. (MEC/SEF, 1998, p. 25).

De acordo com a Base Nacional Curricular Comum para o Ensino Médio (2017), a educação básica deve valorizar e utilizar os conhecimentos historicamente construídos sobre o mundo físico, social, cultural e digital para entender e explicar a realidade, continuar aprendendo e colaborar para a construção de uma sociedade justa, democrática e inclusiva. Além desses princípios, deve estar atenta a

valorizar a diversidade de saberes e vivências culturais e apropriar-se de conhecimentos e experiências que lhe possibilitem entender as relações próprias do mundo do trabalho e fazer escolhas alinhadas ao exercício da cidadania e ao seu projeto de vida, com liberdade, autonomia, consciência crítica e responsabilidade (BRASIL, 2017, p.09)

exercitar a empatia, o diálogo, a resolução de conflitos e a cooperação, fazendose respeitar e promovendo o respeito ao outro e aos direitos humanos, com acolhimento e valorização da diversidade de indivíduos e de grupos sociais, seus saberes, identidades, culturas e potencialidades, sem preconceitos de qualquer natureza. (BRASIL, 2017, p.10).

Tais excertos corroboram com a perspectiva cidadã para uma educação geográfica atenta às transformações sociais e à diversidade na sociedade brasileira. Pertinente a este debate, as competências e habilidades de aprendizagem apregoadas a partir do ensino das Ciências Humanas como itinerário formativo tem focado na

exploração de noções de temporalidade, espacialidade e diversidade (de gênero, religião, tradições étnicas etc.); conhecimentos sobre os modos de organizar a sociedade e sobre as relações de produção, trabalho e de poder, sem deixar de lado o processo de transformação de cada indivíduo, da escola, da comunidade e do mundo (BRASIL, 2017, p.547).

Nesse sentido, a Geografia enquanto uma ciência humana e social tem o desafio de apresentar aos alunos habilidades para "reconhecer e combater as diversas formas de desigualdade e violência, adotando princípios éticos, democráticos, inclusivos e solidários, e respeitando os Direitos Humanos" (BRASIL, 2017, p.558). Para isso, os/as 
alunos/as precisam adquirir a maneira de pensar o espaço através da linguagem própria da geografia a partir da ação de localizar, compreender e atuar no mundo complexo, problematizar a realidade, formular proposições, reconhecer as dinâmicas existentes no espaço geográfico, pensar e atuar criticamente em sua realidade tendo em vista a sua transformação. Para isso, a geografia escolar precisa tomar partido nessa tarefa, referendando temas socialmente relevantes para além dos conteúdos estabelecidos nos currículos oficiais e, portanto, a temática racial, faz-se presente.

\section{CURRÍCULO REFERÊNCIA DE GEOGRAFIA DA REDE ESTADUAL DO} ESTADO DE GOIÁS E AS POSSIBILIDADES DO ENSINO DA TEMÁTICA

\section{RACIAL}

O estudo da Geografia na escola é, segundo a Base Nacional Curricular Comum para o Ensino Fundamental (2017), uma oportunidade para compreender o mundo em que se vive, na medida em que esse componente curricular aborda as ações humanas construídas nas distintas sociedades existentes nas diversas regiões do planeta. Portanto, é a partir de uma educação geográfica que se torna possível formar ou construir um conceito de identidade, seja

na compreensão perceptiva da paisagem, que ganha significado à medida que, ao observá-la, nota-se a vivência dos indivíduos e da coletividade; nas relações com os lugares vividos; nos costumes que resgatam a nossa memória social; na identidade cultural; e na consciência de que somos sujeitos da história, distintos uns dos outros e, por isso, convictos das nossas diferenças (BRASIL, 2017, p.355).

Salienta-se que o desenvolvimento do pensamento geográfico seja desenvolvido a partir da vivência dos sujeitos em suas relações interpessoais e que formem conceitos relativos à compreensão da realidade a partir do raciocínio geográfico. Para o Documento Curricular para Goiás (DCGO) elaborado em 2019, este princípio é um campo de possibilidade para a defesa de uma educação geográfica comprometida com a criticidade, a criatividade e a formação cidadã. $O$ desenvolvimento do raciocínio geográfico é compreendido a partir do domínio de algumas operações cognitivas (Quadro 1). 
De maneira pragmática, o desenvolvimento desta estrutura de raciocínio possibilita aos alunos a compreensão dos fenômenos espaciais, naturais e antrópicos. A divisão das unidades temáticas no DCGO obedece ao cumprimento da aquisição de habilidades e competências gerais de áreas e especificas de geografia contidas na BNCC (2017) que promovem o pensar sobre

as relações socioambientais no espaço em que ele ocupa e no mundo; reconhecer a si e ao outro como identidades diferentes, compreendendo a diversidade sociocultural de forma a exercitar o respeito à diferença em uma sociedade plural e promover os direitos humanos; compreender as diferentes linguagens e tecnologias permitindo agir com autonomia e responsabilidade mediante as situações por eles vivenciadas, com base em argumentações voltados para o bem comum e a construção de uma sociedade justa, democrática e inclusiva (DCGO, 2019, p.77).

Podemos verificar que as orientações do DCGO estão em consonância com a perspectiva da educação integral e da formação de cidadãos críticos, objetivando a percepção dos/as estudantes sobre sua posição e atuação no mundo e que sejam observadores espaciais capazes de provocar transformações socioespaciais.

Quadro1. Descrição dos princípios do raciocínio geográfico segundo a BNCC (2017). 


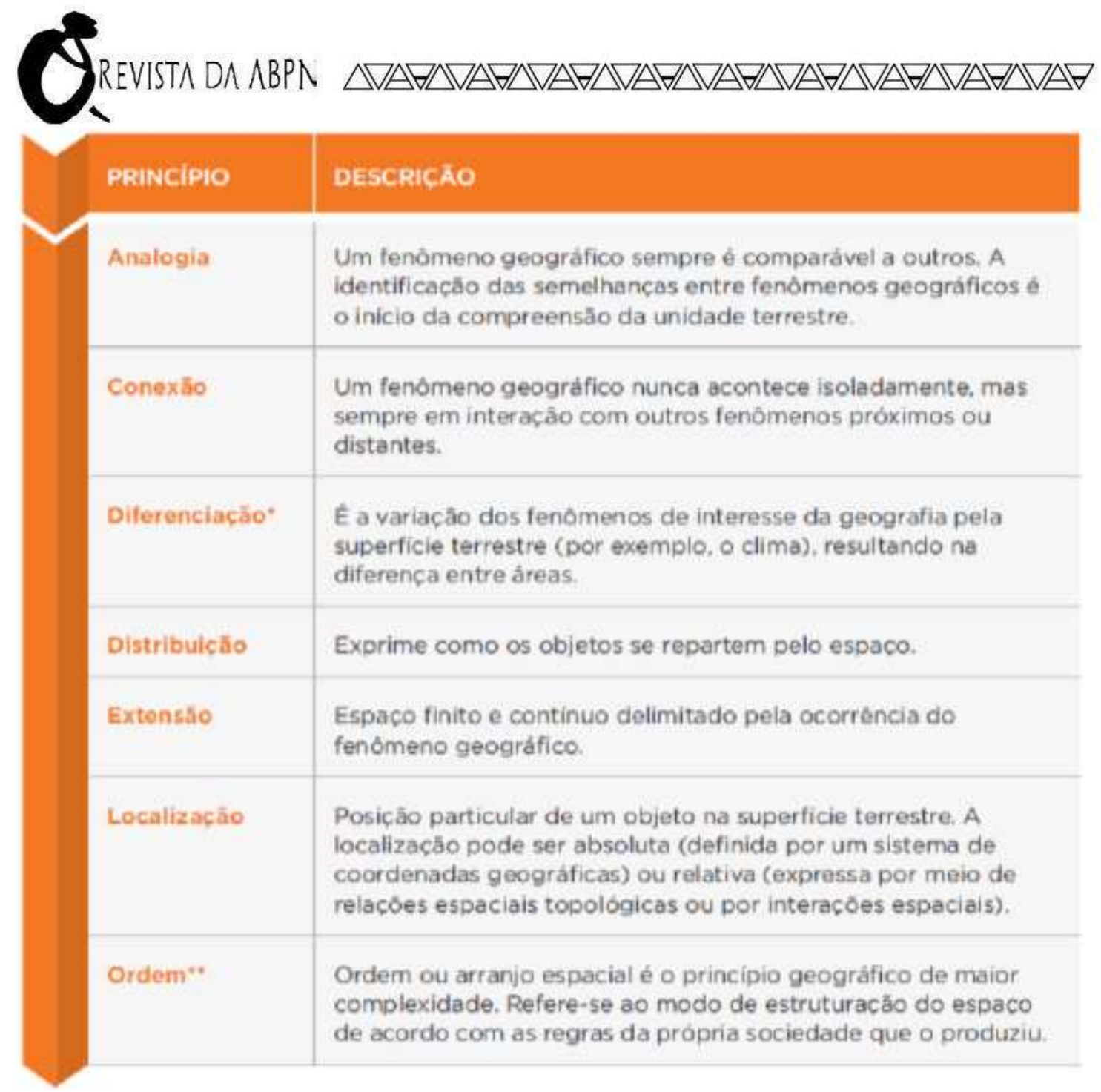

Fonte: BRASIL, 2017.

Ao analisar as unidades temáticas, objetos de conhecimento e habilidades, verificamos que em cada série há grupos de conteúdos em que a temática racial ou étnica perpassa e se concretiza. No $6^{\circ}$ ano, na unidade temática "O sujeito e seu lugar no mundo" há o conteúdo "Povos originários brasileiros e goianos" com o objetivo de analisar modificações de paisagens por diferentes grupos sociais, destacando os povos originários, os quilombolas e as comunidades tradicionais de Goiás.

No $7^{\circ}$ ano, na unidade temática "Conexões e escalas" há o conteúdo "Diversidade étnico-cultural e racial" com o objetivo de analisar a distribuição espacial da população brasileira, considerando os indicadores socioeconômicos, a diversidade étnico-cultural e racial, de sexo/gênero e de idade nas regiões brasileiras. No $8^{\circ}$ ano, na unidade temática “Conexões e escalas” são apresentados conteúdos específicos para a realidade do

Revista da ABPN • v. 12, n. Ed. Especial - Caderno Temático: “Geografias Negras" • abril de 2020, p. 273-291 
continente africano, diferenças e desigualdades das grandes cidades latino-americanas que levam a uma discussão sobre a segregação espacial. No $9^{\circ}$ ano na unidade temática "Mundo do trabalho", os conteúdos "Manifestações culturais de minorias étnicas, Identidade cultural de diferentes povos e Movimentos sociais" visam identificar e conhecer as diferentes manifestações culturais de minorias étnicas como forma de compreender a multiplicidade cultural na escala mundial, defendendo o princípio do respeito à diversidade sociocultural (DCGO, 2019).

A partir da consulta ao documento curricular de referência para a atuação dos professores de geografia do ensino básico, reforçamos que a geografia escolar tem em sua constituição instrumentos e referenciais para o ensino das relações étnico-raciais com criticidade, aproveitando a multiescalaridade sobre negros/as e indígenas para além da cultura.

A participação do/a negro/a na formação da população brasileira pode ser conduzida a partir da superação dos estereótipos e de um reconhecimento responsável da função social da geografia em promover práticas cidadãs, pensando na dimensão espacial das relações de poder. É comungar com a afirmação de Souza (2016) sobre o reconhecimento da escola como um ambiente que envolve uma diversidade cultural e exatamente por isso propicia um espaço crítico, de aceitação e de valorização da diferença. E tais ações podem começar ou se desenvolverem nas aulas de geografia. Vemos que os documentos orientadores para o ensino de geografia na educação básica em Goiás reconhecem a importância do ensino das relações étnico-raciais como campo relevante na ciência geográfica, no entanto, o desafio para a implementação desta prática pelo/a professor/a incide sobre a organização cronológica na escola, a condução de conteúdos considerados prioritários e a formação adequada para o tratamento das diferenças.

\section{CONSIDERAÇÕES FINAIS}

Com base em informações levantadas no DCGO (2019), pode se destacar abertura para a discussão relacionada às relações étnico-raciais no ensino de Geografia, trazendo conteúdos que abrangem fatos e temas para além de dados demográficos e visão geral 
sobre o continente africano. Por ora, tal documento traz pontos importantes para a discussão da temática étnico-racial no Brasil e em Goiás.

Salientamos que, embora o Currículo apresente possibilidades de tratamento da temática enquanto um tema socialmente relevante, nota-se, a partir de observações e vivencias em estágio e práticas de ensino, dificuldade e desinteresse da comunidade escolar em criar na escola um espaço que propicie um debate sobre as diferenças e sobre o/a negro/a na formação social brasileira.

Contudo percebe-se que há muito a ser feito para despertar uma abertura e interesse para o ensino dessa temática nos/as professores/as de geografia. É preciso refletir sobre a contribuição e o papel que professores/as podem assumir na transformação para um pensamento crítico e uma aprendizagem mais equânime.

Vemos que muitos/as professores/as de Geografia não conhecem a lei 10.639/03 Questionando a um professor de geografia sobre a lei 10.639/03 e, quando questionados sobre menciona-la em suas aulas, afirmam que é uma lei especifica para o ensino de história, contrariando os princípios normativos impetrados na lei que a prevê em todas as áreas do ensino. Reflete, assim, a falta de conduta pedagógica de docentes/as e gestores/as sobre a realidade racial de todos/as e, em específico na geografia escolar, a dificuldade e não priorização de temas socialmente relevantes e suas espacialidades.

\section{REFERÊNCIAS BIBLIOGRÁFICAS}

ABREU, Martha; MATTOS, Hebe. Em torno das "Diretrizes curriculares nacionais para a educação das relações étnico-raciais e para o ensino de história e cultura afro-brasileira e africana": uma conversa com historiadores. Estud. hist. (Rio J.) vol.21 no.41, Rio de Janeiro Jan./June 2008.

BENEVIDES, Maria Vitória. Cidadania e Direitos Humanos. In: CARVALHO, José Sérgio (Org.) Educação, Cidadania e Direitos Humanos. Petrópolis,RJ: Vozes, 2004.

BOTELHO. D. Aya nini (coragem). Educadores e educadoras no enfrentamento de práticas racistas em espaços escolares. São Paulo e Havana. Dissertação (Mestrado em Integração da América latina) ProlamUSP. São Paulo, 2000.

BRASIL. Ministério da Educação: Secretaria de Educação Básica. Base Nacional Curricular Comum para o Ensino Médio. Brasília, 2017.

CAVALLEIRO, Eliane. Do silêncio do lar ao silêncio escolar: racismo, preconceito e discriminação na educação infantil. Dissertação de Mestrado. Faculdade de Educação da Universidade de São Paulo. 1998. 
CAVALCANTI, Lana; SOUZA, Vanilton Camilo. A formação do professor de geografia para atuar na educação cidadã. Scripta Nova. Revista Eletronica de Geografia y Ciencias Sociales, v. $18,2014$.

DIAS, Lucimar Rosa. Quantos passos já foram dados? A questão de raça nas leis educacionais. Da LDB de 1961 a Lei 10.639. In: ROMÃO, Jeruse (org) História da Educação do Negro e outras histórias. Secretaria de Educação Continuada, Alfabetização e Diversidade. - Brasília: Ministério da Educação, Secretaria de Educação Continuada, Alfabetização e Diversidade, 2005

DOCUMENTO CURRICULAR PARA GOIÁS- Ampliado. Secretaria Estadual de Educação e Cultura, 2019.

GOMES, Nilma Lino. Diversidade étnico-racial, inclusão e equidade na educação brasileira: desafios, políticas e práticas, $R B P A E-$ v.27, n.1, p. 109-121, jan./abr. 2011

MOTA, Edimilson A. Abordagem da Lei 10.639/03 no livro didático de Geografia: leitura de imagem. In: PORTUGAL, Jussara F. Educação geográfica: temas contemporâneos. Salvador: EDUFBA, 2017. Pp.75-92.

MUNANGA, Kabengele. Educação e Diversidade Cultural. Cadernos PENESB: discussões sobre o negro na contemporaneidade e suas demandas, 37-54, 2008.

PEREIRA, Márcia Moreira; SILVA, Maurício. Percurso da Lei 10639/03: antecedentes e desdobramentos. Linguagens \& Cidadania, v. 14, n. 1, 2012.

PEREIRA, Nilton Mullet. Diversidade e diferença: problemas teóricos e pedagógicos. In: TONINI, Ivaine M.; KAERCHER, Nestor André (orgs.) Curso de aperfeiçoamento, produção de material didático para diversidade. Porto Alegre: Evangraf, UFRGS, 2011.

SANTOS, Renato Emerson dos. A Lei 10.639 e o Ensino de Geografia: Construindo uma agenda de pesquisa-ação. Revista Tamoios ano VII, No 1, 2011

SOUZA, Lorena Francisco de. As relações Etnico-raciais na Geografia Escolar: Desafios Metodológicos e Pedagógicos. Revista Produção Acadêmica - Núcleo de Estudos Urbanos Regionais e Agrários, Vol. 2, no 2, p. 4-19, dezembro/2016.

TONINI, Ivaine; KAERCHER, Nestor André. A diferença como possibilidade de discutir a desigualdade e combater o preconceito: A geografia que faz diferença. In: (Orgs.). Movimentos no ensinar geografia: rompendo rotações. Porto Alegre: Evangraf, 2015. p. 55- 71. ; GOULART, Ligia Beatriz; MARTINS, Rosa Elisabete M. Wypyczynski et al. (orgs.). $O$ ensino da geografia e suas composições curriculares. Porto Alegre: UFRGS, 2011.

Recebido em 20/02/2020

Aprovado em 30/03/2020 